\title{
The prevalence of pelvic organ prolapse symptoms and signs and their relation with bladder and bowel disorders in a general female population
}

\author{
Marijke C. Ph. Slieker-ten Hove • Annelies L. Pool-Goudzwaard • \\ Marinus J. C. Eijkemans • Regine P. M. Steegers-Theunissen • Curt W. Burger • \\ Mark E. Vierhout
}

Received: 24 November 2008 /Accepted: 21 April 2009/Published online: 15 May 2009

(C) The Author(s) 2009. This article is published with open access at Springerlink.com

\begin{abstract}
Introduction and hypothesis In selected populations, pelvic organ prolapse (POP) was associated with bladder/bowel symptoms, but data on the general female population are lacking. Our aim was to obtain normative data on the prevalence of POP and pelvic floor dysfunction (PFD) symptoms and signs and to identify associations.

Methods Validated questionnaires on POP and PFD (urogenital distress inventory, (UDI) and defaecation distress inventory (DDI)) were sent to a general population of 2,979
\end{abstract}

Summary POP was strongly associated with obstructive bowel disorders. Therefore, preventive strategies should be developed.

M. C. P. Slieker-ten Hove $(\bowtie)$

Cobra Research Institute, Pelvic floor research,

Amersfoort, The Netherlands

e-mail: m.slieker@somt.nl

M. C. P. Slieker-ten Hove • R. P. M. Steegers-Theunissen •

C. W. Burger

Department of Obstetrics and Gynaecology, Erasmus MC,

University Medical Centre,

Rotterdam, The Netherlands

\author{
A. L. Pool-Goudzwaard \\ Department of Neuroscience, Erasmus MC, \\ University Medical Centre, \\ Rotterdam, The Netherlands
}

\section{J. C. Eijkemans}

Department of Public Health, Erasmus MC,

University Medical Centre,

Rotterdam, The Netherlands women (aged 45-85 years). Data were analysed using the Kruskal-Wallis test, chi square test and Spearman's rank correlation coefficient.

Results Response rate was $62.7 \%$. Associations between POP stage and parity $(0.002)$ and vaginal bulging $(<0.001)$ are significant. Anatomical locations of POP and PFD symptoms correlated significantly with incontinence of flatus, feeling anal prolapse, manual evacuation of stool, vaginal bulging, constipation and pain during faecal urge $(p \leq 0.005)$.

R. P. M. Steegers-Theunissen

Department of Epidemiology, Erasmus University Medical Centre, Rotterdam, The Netherlands

\section{R. P. M. Steegers-Theunissen}

Department of Paediatrics/Paediatric Cardiology, Erasmus MC, University Medical Centre,

Rotterdam, The Netherlands

R. P. M. Steegers-Theunissen

Department of Clinical Genetics, Erasmus MC,

University Medical Centre,

Rotterdam, The Netherlands

C. W. Burger

Division of Gynaecologic Oncology, Erasmus MC,

University Medical Centre,

Rotterdam, The Netherlands

M. E. Vierhout

Department of Obstetrics and Gynaecology,

Radboud University Nijmegen Medical Centre,

Nijmegen, The Netherlands 
Conclusions Strategies should be developed to alleviate obstructive bowel disorders associated with POP.

Keywords Prevalence - Incontinence - Bladder - Bowel · Pelvic floor disorders $\cdot$ POPQ

\section{Introduction}

Dysfunction of the pelvic floor (PFD) can cause many different symptoms, such as urinary or faecal incontinence $[1,2]$, obstructed micturition or defaecation [3, 4], sexual disorders [5-7], perineal pain [8] and vaginal bulging (a specific symptom of clinically relevant pelvic organ prolapse, POP) [9]. PFD symptoms are strongly associated with the female gender [10]. Parity is strongly associated with the development of PFD [11]. The impact of PFD symptoms is substantial and multidimensional [12], which underlines the need to gain more insight into associations between the different symptoms.

In clinical practice, women often present with a complexity of POP and bladder and/or bowel symptoms. Nevertheless, only weak correlations were found between POP and other bladder/bowel symptoms [13, 14]. It appears that women with advanced POP are less likely to have stress urinary incontinence (SUI) but more likely to have obstructed micturition: SUI was only correlated with mild POP [15]. Recently, a stronger link has been demonstrated between bladder/bowel symptoms and vaginal descent [16]. Interestingly, not only the pelvic organ prolapse quantification (POPQ) stages were tested for correlations with bladder and bowel function, but also the anatomical location of POP were studied using the nine-point notation of the POPQ. Strong associations were found between bladder pain, obstructive bladder symptoms and the lowest point of the most dependent portion of the upper part of the anterior vaginal wall (point $\mathrm{Ba}$ ). and between bowel incontinence and the lowest point of most dependent portion of the upper part of the posterior vaginal wall (point Bp). Furthermore, the C-point was associated with vaginal bulging. This suggests that progression of vaginal descent over time is more strongly associated with these bladder/bowel symptoms than has so far been demonstrated. However, an association was found between POPQ location and bladder/bowel symptoms in a selected group of menopausal women, but the selection might have distorted the outcome. In 2005, Kahn et al. reported an association between faecal straining in combination with anterior vaginal wall and perineal descent in a selected population of women who visited the gynaecological clinic [17].

It is unclear whether the associations between POP and bladder/bowel symptoms are also present in a general female population.
We therefore conducted a cross-sectional study to obtain normative data on the prevalence of pelvic floor dysfunction symptoms using questionnaires and vaginal examination. POPQ scores were tested in relation with age and parity. We also analysed associations between the pelvic floor symptoms and POPQ stages as well as the nine-point notation.

\section{Materials and methods}

A cross-sectional study was performed on a general population of Dutch, mostly white women aged 45 to 85 years. Figure 1 presents the flowchart of the study.

The total population of women aged 45-85 years, registered in the office records of eight out of nine general practitioners from the town of Brielle (near Rotterdam, the Netherlands), were approached to participate in the present study. Since all inhabitants have the obligation to be registered at a general practitioners clinic, the study population contained $95 \%$ of all women in Brielle in this age category. The women were sent information about the study and enrolled by filling out an informed consent form. They were offered three options: to sign a refusal form, to fill out the questionnaire only or to fill out the questionnaire and undergo vaginal examination.

All the women were asked to complete a self-report questionnaire. Non-responders received a reminder 8 weeks after the first contact that contained the same questionnaire. The data were collected anonymously. To avoid selection bias, non-responders were invited to complete a short questionnaire that comprised five questions about: age, parity, presence of stress urinary incontinence (yes/no), faecal incontinence (yes/no) and feeling a vaginal bulge (yes/no). To encourage a high response to the questionnaire, we used envelopes with the name and logo of the Erasmus University, coloured paper and stamped-addressed return envelopes [18].

The questionnaire used in this study combined Dutchvalidated versions of pelvic floor questionnaires, such as the urogenital distress inventory (UDI) [19] and the defaecation distress inventory (DDI) [2]. In addition, women were asked about body mass index (BMI) ethnicity, educational level, parity, menopausal status, hormone replacement therapy (HRT), smoking, previous pelvic floor surgery, family history and heavy physical work currently or in the past.

Women were classified as symptomatic if they reported feeling and/or seeing vaginal bulging on the questionnaires. Differences in vaginal bulging, stress urinary incontinence (urine loss $\geq 1 /$ month with at least a little bother) and faecal incontinence (loss of fluid or solid stool $\geq 1 /$ month with at least little bother) were tested between the non-responders and responders using the outcomes on the UDI and DDI. Women were defined symptomatic on bladder and bowel symptoms with the same criteria as mentioned for the vaginal bulging. Frequency of symptoms had to be reported 
Fig. 1 Flowchart of the study

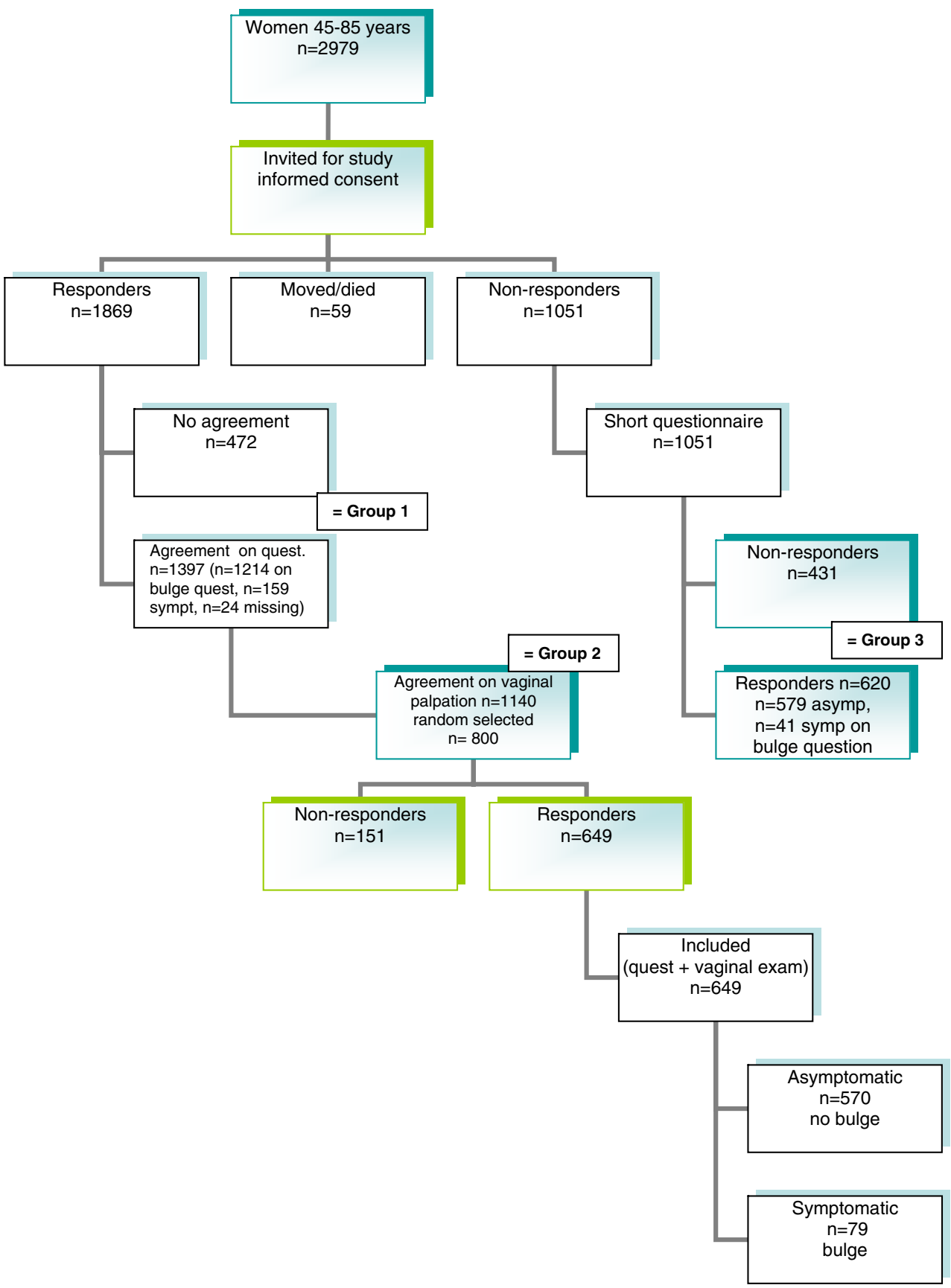

at least $\geq 1 /$ month and the bother was reported at least as 'a little bother'.

Differences in vaginal bulging, stress urinary incontinence and faecal incontinence (loss of solid stool $\geq 1 /$ month with at least little bother) were tested between the nonresponders and responders using the outcomes on the UDI and DDI.

\section{Vaginal examination}

From all the participants who gave informed consent to undergo vaginal examination, we randomly selected women for POPQ measurement (all response forms of the women were registered with a number that identified the age and they were at random taken by a research assistant). The POPQ was introduced by the International Continence Society (ICS). It has become widely accepted and proven to be valid [20] and reliable [21]. One gynaecologist and one physiotherapist performed the vaginal examinations (every woman was examined by the gynaecologist or the physiotherapist). They practiced the vaginal examination protocol until both examiners were scoring same results. POPQ measurements were carried out in conformity with the ICS standardisation report [20]. After each examination, all the details were entered into 
the three-by-three POPQ grid. The two examiners were blinded to the results of the questionnaire. The women were asked to empty their bladder before the examination.

Women were assigned to one of five ordinal stages of prolapse $(0-4)$ in accordance with the POPQ grading system. All methods, definitions and descriptions were in line with the ICS. Furthermore, we used the notation of the nine-point grid of the POPQ to analyse possible correlations between the different points of the POPQ.

\section{Statistical analysis}

Patient characteristics were compared between the POPQ stages and the symptomatic and asymptomatic women by means of the Kruskal-Wallis test and the chi square test for continuous and categorical variables, respectively. Spearman's rank correlation coefficient was calculated between the components of the nine-point grid of the POPQ and the items from the UDI and DDI questionnaires. The analyses were performed using the Statistical Package for Social Science (SPSS Inc) 15.0. The Medical Ethics Research Committee (METC) of the Erasmus Medical Centre in Rotterdam, the Netherlands, approved this study.

\section{Results}

Response rate

The response rate to the questionnaire was $62.7 \%(1,869 /$ $2,979)$. In the group of 1,869 responders, $472(25.2 \%)$ women refused to participate, 1,397 (74.8\%) women (group 1 in Table 1) agreed to fill out the large questionnaire and 1,140 (group $2 ; 60.9 \%$ ) agreed to fill out the questionnaire and undergo vaginal examination. From group 2, 800 women were selected at random and sent an invitation to undergo vaginal examination. All response forms of the women were registered with a number that identified the age and they were, at random, taken by a research assistant. Six-hundred fortynine women participated (81.1\%) in the vaginal examination. So, of the total study group of $1,397,46.4 \%$ were vaginally examined. The study group of 649 women was stratified into an asymptomatic control group $(n=570)$ and a symptomatic $(n=79)$ group in which the women had reported seeing and/or feeling vaginal bulging. In the non-responder group 3, 59\% returned the completed short questionnaire (620/ $1,051)$. Vaginal bulging was reported by $6.7 \%(n=41)$ of this non-responder group versus $9.8 \%$ in the responder group $(135 / 1,397)$. Combining the data on the large- and short questionnaires from the responders (group 1) and the initial non-responders (group 3; 1,397+620=2,017) revealed a prevalence rate of $8.7 \% \quad(n=176)$ of feeling vaginal bulging.
Baseline characteristics

Baseline characteristics of the total study population and the different groups (overall group 1, the vaginal examination group 2 divided into a symptomatic group (seeing and/or feeling vaginal bulging) and an asymptomatic group and the non-responder group 3) are presented in Table 1.

No significant differences were found between group 1 and group 3, or between the asymptomatic and symptomatic women in group 2 .

\section{Prevalence}

The prevalence of POP per stage in relation with age in our general population is presented in Table 2. No significant association could be demonstrated between increasing age and increasing POP. In the analysis of the prevalence of POP in relation with parity, there was a significant association between POP stage and a parity of two (0.002). No significant association was demonstrated between POP stage and a parity of $\geq 3$.

In the vaginal examination group, the symptoms of pelvic floor dysfunction are shown in relation with the POPQ stages in Table 3. The only significant correlation between POP stage and bladder and/or bowel symptoms was with vaginal bulging $(p<0.001)$. In Table 4 , the symptoms of pelvic floor dysfunction are presented versus the nine-point notation of the POPQ measurement. Significant correlations (shown with asterisks) were found with incontinence of flatus, anal prolapse, manual evacuation of stool per vagina and/or anus, vaginal bulging, constipation and pain during faecal urge $(p \leq 0.05)$. This demonstrated a strong association between the posterior vaginal wall and bowel disorders, as well as an association between bladder disorders and the anterior vaginal wall. Table 5 presents the detailed POPQs in relation with feeling and/or seeing vaginal bulging. The only non-significant locations were the genital hiatus, perineal length and total vaginal length.

\section{Discussion}

In this study on mainly white women aged 45-85 years from the general population, the prevalence of bladder and bowel disorders was high. We found a relation between the anterior compartment prolapse and urge urinary incontinence as well as a significant association between posterior compartment prolapse and bowel disorders. Analysis of the anatomical location of the POP led to these significant findings. The overall POPQ stage did not show any associations besides the symptom of vaginal bulging. 
Table 1 Characteristics of total study group, the vaginal exam group and the non-responders group

\begin{tabular}{|c|c|c|c|c|c|c|}
\hline \multirow[t]{2}{*}{$\begin{array}{l}\text { Characteristics of the study } \\
\text { population }\end{array}$} & \multicolumn{3}{|c|}{ Questionnaire Group 1} & \multicolumn{2}{|c|}{$\begin{array}{l}\text { Questionnaire and vaginal } \\
\text { exam Group } 2\end{array}$} & \multirow{2}{*}{$\begin{array}{l}\text { Non- responders } \\
\text { questionnaire Group } 3 \\
\text { Non-responders }\end{array}$} \\
\hline & Questionnaire total & $\begin{array}{l}\text { Total group } \\
\text { bulging, no }\end{array}$ & $\begin{array}{l}\text { Total group } \\
\text { bulging, yes }\end{array}$ & $\begin{array}{l}\text { Vaginal Exam } \\
\text { Bulging, no }\end{array}$ & $\begin{array}{l}\text { Vaginal exam } \\
\text { bulging, yes }\end{array}$ & \\
\hline \multirow{2}{*}{$\begin{array}{l}\text { Mean age (range } \\
45-84 \text { years) }\end{array}$} & $n=1,397$ & $n=1,214$ & $n=159(11.4 \%)$ & $n=570$ & $n=79(12.2 \%)$ & $n=620$ \\
\hline & $58.0(\mathrm{SD} \pm 9.2)$ & $57.8(\mathrm{SD} \pm 9.1)$ & $59.0(\mathrm{SD} \pm 9.5)$ & $58.0(\mathrm{SD} \pm 8.9)$ & $59.3(\mathrm{SD} \pm 9.1)$ & 59.2 \\
\hline Mean BMI & $25.6(\mathrm{SD} \pm 3.9)$ & $25.6(\mathrm{SD} \pm 4.0)$ & $25.5(\mathrm{SD} \pm 3.4)$ & $25.6 \pm 3.7$ & $25.5 \pm 3.1$ & \\
\hline Race & $(n=1,340)$ & $n=1,165$ & $(n=153)$ & $(n=551)$ & $(n=78)$ & \\
\hline White & $1,351(98.4)$ & $1,172(88.2)$ & $156(98.1)$ & $545(98.7)$ & $78(100)$ & \\
\hline Non-white & $20(1.5)$ & $18(1.3)$ & $1(0.6)$ & $7(1.3)$ & 0 & \\
\hline Educational level & $(n=1,374)$ & $(n=1,193)$ & $(n=158)$ & $(n=556)$ & $(n=78)$ & \\
\hline Primary only & $139(9.9)$ & $117(9.8)$ & $18(11.4)$ & $63(11,3)$ & $7(8.9)$ & \\
\hline Intermediate & $1,039(75.6)$ & $907(76)$ & $117(74.1)$ & $420(75.5)$ & $60(76.9)$ & \\
\hline Higher & $196(14.3)$ & $169(14.2)$ & $23(14.6)$ & $493(88.6)$ & $71(91)$ & \\
\hline Median parity & 2 & 2 & 2 & 2 & 2 & 2 \\
\hline 0 & $120(8.9)$ & $110(9.4)$ & $9(5.8)$ & $46(8.3)$ & $3(3.8)$ & $67(10.6)$ \\
\hline 1 & $215(16)$ & $184(15.8)$ & $25(16.3)$ & $71(12.9)$ & $13(16.6)$ & $102(16.1)$ \\
\hline 2 & $675(50.3)$ & $582(49.9)$ & $87(56.8)$ & $273(49.5)$ & $46(58.9)$ & $277(43.6)$ \\
\hline$\geq 3$ & $387(28.8)$ & 338 (29) & $38(24.8)$ & $161(29.2)$ & $16(20.5)$ & $180(28.3)$ \\
\hline Menopausal status & $(n=1,383)$ & $(n=1,202)$ & $(n=159)$ & $(n=557)$ & $(n=79)$ & \\
\hline (Pre)menopausal & 374 (27) & $332(27.6)$ & $39(24.5)$ & $151(27.1)$ & $16(20.2)$ & \\
\hline Postmenopausal & $1,009(72.9)$ & $870(72.4)$ & $120(75.5)$ & $406(72.9)$ & $63(79.7)$ & \\
\hline (Pre)menopausal with HRT & $(n=1,361)$ & $(n=332)$ & $(n=38)$ & $(n=551)$ & $(n=79)$ & \\
\hline (Pre)menopausal with HRT & $24(1.7)$ & $22(6.6)$ & $2(5.3)$ & $9(1.6)$ & 0 & \\
\hline Postmenopausal with HRT & $63(4.6)$ & $52(15.6)$ & $10(26.3)$ & $23(4.2)$ & $7(8.9)$ & \\
\hline Smoking & $(n=1,382)$ & $(n=1,202)$ & $(n=158)$ & $(n=556)$ & $(n=78)$ & \\
\hline Current Smoker & $280(20.2)$ & $248(22.4)$ & $29(10.5)$ & $117(21)$ & $16(20.5)$ & \\
\hline Ever Smoker & $345(46.3)$ & $300(46.6)$ & $43(12.5)$ & $158(54.8)$ & $25(64.1)$ & \\
\hline Surgical history & $(n=1,384)$ & $(n=1,202)$ & $(n=159)$ & $(n=557)$ & $(n=79)$ & \\
\hline Prolapse & $103(7.4)$ & $71(5.9)$ & $29(18.2) * 0.000$ & $37(6.6)$ & $16(20.2)$ & \\
\hline Incontinence & $47(3.4)$ & $36(2.9)$ & $10(6.4) 0.032$ & $21(3.8)$ & $3(3.9)$ & \\
\hline Hysterectomy & $234(16.9)$ & $191(15.8)$ & 36 (22.6) 0.024 & $85(15.3)$ & $20(25.3)$ & \\
\hline Family history & $(n=985)$ & $(n=874)$ & $(n=97)$ & $(n=397)$ & $(n=44)$ & \\
\hline \multirow[t]{2}{*}{ Mother POP } & $359(26.4)$ & $304(34.8)$ & $50(51.5) * 0.001$ & $139(35)$ & $22(50)$ & \\
\hline & $(n=870)$ & $(n=784)$ & $(n=86)$ & $(n=357)$ & $(n=41)$ & \\
\hline Mother UI & $258(29.6)$ & $222(28.3)$ & 36 (41.9) 0.008 & $106(29.7)$ & $16(39)$ & \\
\hline Heavy physical work & $n=1,381$ & $(n=1,198)$ & $(n=159)$ & $(n=553)$ & $(n=79)$ & \\
\hline \multirow[t]{2}{*}{ Current } & $269(19.3)$ & 227 (18.9) & $39(24.5)$ & 109 (19.7) & $18(22.8)$ & \\
\hline & $n=1,384$ & $(n=1,201)$ & $(n=159)$ & $(n=556)$ & $(n=79)$ & \\
\hline Ever & $619(44.3)$ & $531(44.2)$ & $78(49.1)$ & $248(44.6)$ & $39(49.3)$ & \\
\hline
\end{tabular}

Prevalence of symptoms according to self-report questionnaires

In our overall group, the prevalence of feeling and/or seeing vaginal bulging in the overall group was $12.1 \%: 9.7 \%$ reported the feeling of vaginal bulging alone. These figures are comparable with the prevalence of $8.3 \%$ (95\% CI 7.3-9.1) reported in a Swedish population study [11]. In another Swedish study, only $4 \%$ had a positive POP score. However, they used other inclusion criteria and dichotomized the study population according to age and they defined a POP as a positive score on the question 'do you experience a sense of heaviness in the lower abdomen'. [22]. MacLennan et al. reported an $8 \%$ prevalence of POP in a general population [10]. They 
Table 2 Overall distribution of POP per age group (\%) used $(p<0.001)$

\begin{tabular}{lrrrrrr}
\hline Age (years) & Stage 0 & Stage 1 & Stage 2 & Stage 3 & Stage 4 & Total \\
\hline $45-50$ & $24(16.4)$ & $66(45.2)$ & $53(36.3)$ & $3(2.1)$ & 0 & 146 \\
$>50-55$ & $39(26.9)$ & $57(39.3)$ & $42(29.0)$ & $7(4.8)$ & 0 & 145 \\
$>55-60$ & $47(34.1)$ & $39(28.3)$ & $45(32.6)$ & $7(5.1)$ & 0 & 138 \\
$>60-65$ & $16(20.5)$ & $30(38.5)$ & $25(32.1)$ & $7(9.0)$ & 0 & 78 \\
$>65-70$ & $21(33.9)$ & $17(27.4)$ & $22(35.5)$ & $2(3.2)$ & 0 & 62 \\
$>70$ & $14(18.9)$ & $26(35.1)$ & $25(33.8)$ & $6(8.1)$ & $3(4.1)$ & 74 \\
Overall & $161(25.0)$ & $235(36.5)$ & $212(33.0)$ & $32(5.0)$ & $3(0.5)$ & 643 \\
\hline
\end{tabular}

defined a positive POP symptom based on the question 'do you have a feeling of something coming down in the vagina.'

Furthermore, their age group was age 15 to $\geq 65$ years (28\% were nulliparous and the number of deliveries in the parous group was unknown). They asked all the questions in a face-to-face interview, which may have led to different answers from those given on self-report questionnaires [23].

Prevalence of signs scored with the POPQ grading system

In our general population, the percentage of women in the five ordinal POPQ stages (0-4) were 25\%, 36.5\%, 33\%, $5 \%$ and $0.5 \%$, respectively.
The prevalence of POP in a general population has only been determined using the POPQ grading system in a few studies. Our percentages in the five POP stages in the asymptomatic group 2, who did not report seeing and/or feeling vaginal bulging were comparable with those in the asymptomatic group in the study by Digesu et al. [24]. However, there was a difference in mean age (48 years), which indicates that age may not be responsible for this comparable result, which also can be concluded from our findings that age and POP stage were not significant associated. In contrast, the data on the symptomatic group differed, probably due the different choice of definition of 'symptomatic'. In their symptomatic group, Digesu et al.

Table 3 Symptoms of pelvic floor disorders in the vaginal examination group versus the POPQ grading system in \%

\begin{tabular}{|c|c|c|c|c|c|c|c|}
\hline & $n$ & Stage 0 & Stage 1 & Stage 2 & Stage 3 & Stage 4 & Overall \\
\hline \multicolumn{8}{|l|}{ Urinary incontinence } \\
\hline Urge urinary incontinence & 625 & 27.8 & 30.1 & 31.7 & 40.0 & 33.3 & 30.5 \\
\hline Stress urinary incontinence & 627 & 53.5 & 59.6 & 54.6 & 43.3 & 33.3 & 53.9 \\
\hline Mixed urinary incontinence & 624 & 22.2 & 25.4 & 25.9 & 16.7 & 0 & 24.2 \\
\hline \multicolumn{8}{|l|}{ Faecal incontinence } \\
\hline Flatus & 638 & 46.9 & 46.4 & 54.5 & 58.1 & 33.3 & 49.6 \\
\hline Fluid stool & 638 & 15.0 & 8.2 & 15.6 & 9.7 & 0 & 12.3 \\
\hline Solid stool & 641 & 3.7 & 2.6 & 5.7 & 6.5 & 0 & 4 \\
\hline \multicolumn{8}{|l|}{ Obstructive micturition } \\
\hline Difficulty emptying bladder & 631 & 14.5 & 17.7 & 20.7 & 33.3 & 33.3 & 18.7 \\
\hline Bladder not empty after micturition & 636 & 26.4 & 24.8 & 33.3 & 40.0 & 33.3 & 28.7 \\
\hline \multicolumn{8}{|l|}{ Obstructive defaecation } \\
\hline False faecal urge & 638 & 27.7 & 30.0 & 35.4 & 29.0 & 33.3 & 31.1 \\
\hline Feeling of anal prolapse & 634 & 15.2 & 12.9 & 19.9 & 16.7 & 66.7 & 16.2 \\
\hline Manual evacuation of stool per vagina & 633 & 12.7 & 14.4 & 16.0 & 22.6 & 33.3 & 15 \\
\hline Manual evacuation of stool per anus & 639 & 8.1 & 7.7 & 10.0 & 6.5 & 0 & 8.4 \\
\hline Frequent straining during defaecation & 637 & 27.8 & 27.9 & 30.2 & 35.5 & 0 & 3.5 \\
\hline Vaginal bulging & 633 & $7.6^{*}$ & $6.9^{*}$ & $15.8^{*}$ & $43.3^{*}$ & $100 *$ & 12.1 \\
\hline Constipation & 637 & 7.5 & 4.3 & 4.7 & 0 & 0 & 5 \\
\hline \multicolumn{8}{|l|}{ Pain } \\
\hline Low abdominal & 634 & 24.7 & 22.7 & 28.7 & 32.3 & 33.3 & 25.7 \\
\hline During faecal urge & 633 & 10.8 & 7.8 & 11.8 & 19.4 & 0 & 10.4 \\
\hline During/after defaecation & 632 & 12.7 & 10.4 & 14.2 & 16.1 & 0 & 13.6 \\
\hline
\end{tabular}

${ }^{*} p$ value $<0.001$ chi square test 
Table 4 Symptoms of pelvic floor disorders versus the nine-point grid of the first notation of the POPQ with significance in italics

\begin{tabular}{|c|c|c|c|c|c|c|c|c|c|}
\hline & aa & ba & c & hg & per & tvl & ap & bp & d \\
\hline \multicolumn{10}{|l|}{ Urinary incontinence } \\
\hline Urge urinary incontinence & -0.03 & $-0.08 * * *$ & 0.01 & -0.06 & 0.06 & -0.02 & 0.05 & 0.03 & -0.01 \\
\hline Stress urinary incontinence & -0.03 & -0.01 & 0.00 & -0.05 & 0.02 & -0.02 & 0.07 & 0.06 & -0.02 \\
\hline Mixed urinary incontinence & 0.02 & 0.06 & -0.02 & 0.04 & -0.06 & -0.01 & -0.06 & -0.05 & 0.00 \\
\hline \multicolumn{10}{|l|}{ Faecal incontinence } \\
\hline Flatus & -0.06 & -0.06 & 0.01 & -0.04 & 0.06 & 0.03 & $-0.09 * * * *$ & $-0.11 * *$ & 0.01 \\
\hline Fluid stool & 0.01 & -0.01 & 0.02 & -0.02 & -0.08 & 0.05 & 0.02 & 0.00 & 0.03 \\
\hline Solid stool & -0.01 & -0.04 & 0.03 & -0.02 & -0.03 & 0.05 & 0.02 & 0.04 & -0.03 \\
\hline \multicolumn{10}{|l|}{ Obstructive micturition } \\
\hline Difficulty emptying bladder & -0.02 & -0.05 & -0.02 & -0.02 & 0.00 & -0.01 & -0.06 & -0.07 & -0.02 \\
\hline Bladder not empty after micturition & -0.03 & -0.02 & -0.03 & -0.04 & -0.07 & 0.00 & -0.07 & -0.04 & -0.06 \\
\hline \multicolumn{10}{|l|}{ Obstructive defaecation } \\
\hline False faecal urge & -0.05 & -0.07 & -0.01 & 0.04 & 0.00 & 0.05 & -0.02 & -0.05 & -0.01 \\
\hline Feeling of anal prolapse & -0.02 & -0.03 & 0.00 & -0.03 & $-0.09 * * * *$ & 0.01 & -0.03 & $-0.08 * * * * *$ & 0.00 \\
\hline Manual evacuation of stool per vagina & -0.04 & 0.01 & -0.01 & -0.02 & 0.06 & 0.00 & $-0.08 * * * * *$ & $-0.11^{*}$ & -0.03 \\
\hline Manual evacuation of stool per anus & -0.02 & -0.01 & -0.04 & 0.07 & $-0.09 * * * *$ & $0.11^{*}$ & -0.02 & -0.02 & -0.06 \\
\hline Frequent straining during defaecation & 0.02 & 0.02 & 0.02 & -0.04 & 0.03 & -0.01 & -0.02 & $-0.09^{*}$ & -0.02 \\
\hline Vaginal bulging & $-0.18^{*}$ & $-0.18^{*}$ & $-0.14^{*}$ & -0.05 & 0.02 & $0.10^{* *}$ & $-0.14^{*}$ & $-0.11^{*}$ & $-0.16^{*}$ \\
\hline Constipation & 0.07 & 0.07 & $0.08 * * *$ & $0.08 * * *$ & -0.05 & 0.02 & 0.05 & 0.06 & 0.03 \\
\hline \multicolumn{10}{|l|}{ Pain } \\
\hline Low abdominal & -0.03 & -0.02 & -0.01 & -0.02 & $-0.10^{*}$ & -0.04 & $-0.09 *$ & -0.06 & -0.04 \\
\hline During faecal urge & -0.04 & -0.04 & -0.08 & -0.01 & -0.04 & -0.04 & -0.04 & -0.07 & -0.05 \\
\hline During/after defecation & -0.01 & 0.00 & 0.01 & 0.03 & -0.02 & -0.02 & 0.00 & -0.03 & -0.03 \\
\hline
\end{tabular}

Spearman's rank correlation coefficient was calculated between the components of the nine-point grid of the POPQ and the items from the UDI and DDI incontinence questionnaires

${ }^{*} p 0.000 ;{ }^{* *} p 0.01 ; * * * p 0.04 ; * * * * p 0.03 ; * * * * * p 0.05$

included all the women with any type of prolapse complaints, such as bladder and bowel dysfunction and those who reported a 'sensation of dragging' or 'a lump or fullness in the vagina'.

In the literature, various populations of women have been studied. At first sight, the results of the prevalence of POP measured with the POPQ seems most comparable with the results reported by Swift [21] and Kahn [17], but they only recruited women who were receiving routine gynaecological health care. Thus, the characteristics of the study populations differed with respect to ethnicity, parity, BMI, age, surgical history and menopausal status, which hampers comparison of the prevalence rates in the POP stages.

In the prevalence study conducted by Nygaard et al., older women were enrolled from the Women's Health Initiative Hormone Replacement (WHIHR) [25]. Their results are not comparable with ours due to the different age groups, BMI and the HRT (mean age 68.2 years, BMI 30.4). Furthermore, according to Nygaard et al., some degree of POP is nearly ubiquitous in older women. However, in our study, we did not observe a significant increase in POP with increasing age. The differences can probably be explained by patient selection, with different HRT scores, BMI and heavy physical work $[26,27]$ in the population studied by Nygaard et al.

Table 5 Detailed POPQ scores in the symptomatic and asymptomatic women with $p$ value $\leq 0.005$ Kruskal-Wallis was used to analyse the median and the range (in parenthesis)

\begin{tabular}{lccc}
\hline & Bulging & No bulging & $p$ value \\
\hline aa & $-2(-3,3)$ & $-3(-3,1)$ & 0.000 \\
ba & $-1(-3,6)$ & $-2(-4,3)$ & 0.000 \\
c & $-5(-8,6)$ & $-6(-9,3)$ & 0.000 \\
gh & $4(2,6)$ & $4(1,8)$ & 0.257 \\
pb & $3(1,6)$ & $3(1,6)$ & 0.601 \\
tvl & $9(5,10)$ & $9(3,11)$ & 0.012 \\
ap & $-2(-3,3)$ & $-3(-3,3)$ & 0.001 \\
bp & $-2(-3,6)$ & $-2(-3,3)$ & 0.005 \\
d & $-7(-9,1)$ & $-7(-9,-1)$ & 0.000 \\
\hline
\end{tabular}

Values in italics are significant 
In our study, POP complaints were present in $3.8 \%$ of the nulliparous women. This indicates that childbirth is not a prerequisite for POP, although Boyle et al. demonstrated that pregnancy was associated with increased POP stages compared to nulliparous women [26]. In our study, the median parity in the symptomatic and asymptomatic groups was similar (2). In the vaginal examination group, there was a significant $(p$ 0.002) increase in POP with increasing parity, especially after the second child (OR 1.8). This is in line with the study by Mant et al. [28] who demonstrated that women with two children were 8.4 times more likely to develop POP that required hospital admission.

Pelvic floor symptoms versus POP signs measured with the POPQ, analysed with the grading system 0-4

In our study, no significant correlations were found between the pelvic floor symptoms of bladder and/or bowel disorders. However, we did find a significant correlation with 'seeing and/or feeling vaginal bulging'. Similar to the results of many other studies [10, 13, 21], we observed strong discrepancies between the symptoms and signs. Therefore, we emphasise the need for a clinically relevant definition of POP that is not only based on anatomical findings, but also on the symptoms.

Pelvic floor symptoms versus POP location measured with the POPQ, analysed with the nine-point notation

Although no significant correlations could be demonstrated between the pelvic floor symptoms and the ordinal POP stage (0-4 of the POPQ), many significant correlations were found between the anatomical locations of the nine-point notation. The presence of urge urinary incontinence was significantly associated with the lowest point of the upper anterior vaginal wall. This has been demonstrated in earlier studies and urge urinary incontinence disappeared or diminished after successful surgical correction of the anterior vaginal wall [29].

Our results differed from those reported by Bradley et al. [16]. Bladder pain and obstructive bladder symptoms were significantly associated with the lowest point of the upper anterior vaginal wall, but not with the presence of urge urinary incontinence. Overall, most of the significant associations were with obstructive bowel disorders: feeling of anal prolapse, manual evacuation of stool per vagina and per anus. Constipation and vaginal bulging were significantly associated with apical support and the genital hiatus. This is in line with the findings reported by Klingele et al. [4]. POP severity was lower in their faecal incontinence group than in their obstructive bowel symptom group. The study by Bradley also demonstrated that vaginal bulging was associated with point $\mathrm{C}$ [16]. Our point $\mathrm{C}$ results contrasted with the study by Kahn [17], in which they did not find any significant association with constipation. However, Kahn et al. reported similar results on the need for manual evacuation of stool and straining associated with the lowest point on the upper posterior vaginal wall (point $\mathrm{Bp}$ ). Therefore, the posterior vaginal wall is strongly associated with bowel disorders, including incontinence of flatus. It is likely that anatomical changes in the posterior vaginal wall are partly responsible for this symptom.

To analyse associations between POP symptoms and signs and bladder/bowel disorders in a general population, the POPQ grading system did not show as many significant associations as the nine-point notation. This is not surprising because the POPQ grading system only takes the most severely prolapsed compartment into account, which is not necessarily the compartment responsible for the most relevant symptoms. This demonstrates the need to present details about compartments when reporting on the prevalence of POP.

\section{Strengths and limitations}

POP varies between different ethnicities [30]. One of the strengths of our study was the ethnic homogeneity, because almost all of the women were white, which eliminated racial bias in the results. Furthermore, broad data were obtained from a large study group using a combination of questionnaires and vaginal examination.

Although this study was performed on a general population, the mean BMI of 25 and the $98 \%$ white race may have negative effects on extrapolation to other general populations. Also some selection bias could be present due to the women who participated in a vaginal examination and perhaps were symptomatic and never sought help in the past. Our data demonstrated important associations between bladder/bowel disorders and POP that will help to support the development of preventive strategies for pelvic floor disorders.

\section{Conclusions}

The prevalence of bladder and bowel disorders was high. Anterior compartment prolapse was related to urge urinary incontinence. Posterior compartment prolapse was associated with bowel disorders. To demonstrate significant associations between the presence of POP and bowel/ bladder disorders, it is essential to analyse not only the overall POPQ stages, but also the prolapse severity in the three compartments. As POP was found to be strongly associated with obstructive bowel disorders, preventive strategies need to be developed. 
Acknowledgement We are very grateful to the women who participated in this study and to Mrs. G.M. Schoenmaker and her group of general practitioners for their hospitality and cooperation in this study. We thank Mrs. G.M. Schoenmaker, MD, from the General Practitioner Group Brielle, The Netherlands, for her assistance and cooperation.

Funding Unrestricted grant from NV Organon, Oss, the Netherlands.

\section{Conflicts of interest None.}

Open Access This article is distributed under the terms of the Creative Commons Attribution Noncommercial License which permits any noncommercial use, distribution, and reproduction in any medium, provided the original author(s) and source are credited.

\section{References}

1. Hunskaar S, Lose G, Sykes D, Voss S (2004) The prevalence of urinary incontinence in women in four European countries. BJU Int 93:324-330

2. Van Brummen HJ, Bruinse HW, Van De Pol G, Heintz AP, Van Der Vaart CH (2006) Defecatory symptoms during and after the first pregnancy: prevalences and associated factors. Int Urogynecol J Pelvic Floor Dysfunct 17:224-230

3. Richter HE, Nygaard I, Burgio KL, Handa VL, Fitzgerald MP, Wren P et al (2007) Lower urinary tract symptoms, quality of life and pelvic organ prolapse: irritative bladder and obstructive voiding symptoms in women planning to undergo abdominal sacrocolpopexy for advanced pelvic organ prolapse. J Urol 178:965-969 discussion 969

4. Klingele CJ, Carley ME, Hill RF (2002) Patient characteristics that are associated with urodynamically diagnosed detrusor instability and genuine stress incontinence. Am J Obstet Gynecol 186:866-868

5. Mouritsen L (2005) Classification and evaluation of prolapse. Best Pract Res Clin Obstet Gynaecol 19:895-911

6. Handa VL, Cundiff G, Chang HH, Helzlouer KJ (2008) Female sexual function and pelvic floor disorders. Obstet Gynecol 111:1045-1052

7. Rogers GR, Villarreal A, Kammerer-Doak D, Qualls C (2001) Sexual function in women with and without urinary incontinence and/or pelvic organ prolapse. Int Urogynecol J Pelvic Floor Dysfunction 12:361-365

8. Albers LL, Borders N (2007) Minimizing genital tract trauma and related pain following spontaneous vaginal birth. J Midwifery Womens Health 52:246-253

9. Tan JS, Lukacz ES, Menefee SA, Powell CR, Nager CW (2005) Predictive value of prolapse symptoms: a large database study. Int Urogynecol J Pelvic Floor Dysfunct 16:203-209 discussion 209

10. Maclennan AH, Taylor AW, Wilson DH, Wilson D (2000) The prevalence of pelvic floor disorders and their relationship to gender, age, parity and mode of delivery. Bjog 107:1460-1470

11. Tegerstedt G, Maehle-Schmidt M, Nyren O, Hammarstrom M (2005) Prevalence of symptomatic pelvic organ prolapse in a Swedish population. Int Urogynecol J Pelvic Floor Dysfunct 16:497-503

12. Swithinbank LV, Donovan JL, Du Heaume JC, Rogers CA, James MC, Yang Q et al (1999) Urinary symptoms and incontinence in women: relationships between occurrence, age, and perceived impact. Br J Gen Pract 49:897-900
13. Ellerkmann RM, Cundiff GW, Melick CF, Nihira MA, Leffler K, Bent AE (2001) Correlation of symptoms with location and severity of pelvic organ prolapse. Am J Obstet Gynecol 185:1332-1337 discussion 1337-1338

14. Weber AM, Walters MD, Ballard LA, Booher DL, Piedmonte MR (1998) Posterior vaginal prolapse and bowel function. Am J Obstet Gynecol 179:1446-1449 discussion 1449-50

15. Burrows LJ, Meyn LA, Walters MD, Weber AM (2004) Pelvic symptoms in women with pelvic organ prolapse. Obstet Gynecol 104:982-988

16. Bradley CS, Zimmerman MB, Wang Q, Nygaard IE (2008) Vaginal descent and pelvic floor symptoms in postmenopausal women: a longitudinal study. Obstet Gynecol 111:1148-1153

17. Kahn MA, Breitkopf CR, Valley MT, Woodman PJ, O’Boyle AL, Bland DI et al (2005) Pelvic Organ Support Study (POSST) and bowel symptoms: straining at stool is associated with perineal and anterior vaginal descent in a general gynecologic population. Am J Obstet Gynecol 192:1516-1522

18. Edwards P, Roberts I, Clarke M, Diguiseppi C, Pratap S, Wentz R et al (2002) Increasing response rates to postal questionnaires: systematic review. BMJ 324:1183

19. Van Der Vaart CH, De Leeuw JR, Roovers JP, Heintz AP (2002) [The influence of urinary incontinence on quality of life of community-dwelling, 45-70 year old Dutch women] De invloed van urine-incontinentie op de kwaliteit van leven bij thuiswonende Nederlandse vrouwen van 45-70 jaar. Ned Tijdschr Geneeskd 144:894-7

20. Bump RC, Mattiasson A, Bo K et al (1996) The standardization of terminology of female pelvic organ prolapse and pelvic floor dysfunction. Am J Obstet Gynecol 175:10-17

21. Swift S (2002) Current opinion on the classification and definition of genital tract prolapse. Curr Opin Obstet Gynecol Oct 14(5):503507

22. Eva UF, Gun W, Preben K (2003) Prevalence of urinary and fecal incontinence and symptoms of genital prolapse in women. Acta Obstet Gynecol Scand 82:280-286

23. Khullar V, Damiano R, Toozs-Hobson P, Cardozo L (1998) Prevalence of faecal incontinence among women with urinary incontinence. Br J Obstet Gynaecol 105:1211-1213

24. Digesu GA, Chaliha C, Salvatore S, Hutchings A, Khullar V (2005) The relationship of vaginal prolapse severity to symptoms and quality of life. Bjog 112:971-976

25. Nygaard I, Bradley C, Brandt D (2004) Pelvic organ prolapse in older women: prevalence and risk factors. Obstet Gynecol 104:489-497

26. O'Boyle AL, Woodman PJ, O'Boyle JD, Davis GD, Swift SE (2002) Pelvic organ support in nulliparous pregnant and nonpregnant women: a case control study. Am J Obstet Gynecol 187:199-102

27. Woodman PJ, Swift SE, O'Boyle AL, Valley MT, Bland DR, Kahn MA et al (2006) Prevalence of severe pelvic organ prolapse in relation to job description and socioeconomic status: a multicenter cross-sectional study. Int Urogynecol J Pelvic Floor Dysfunct 17:340-345

28. Mant J, Painter R, Vessey M (1997) Epidemiology of genital prolapse: observations from the Oxford Family Planning Association Study. Br J Obstet Gynaecol 104:579-585

29. Batra AK, Mathews R, Lopresti A (1997) Initial experience with the modified vaginal wall sling in the treatment of female stress urinary incontinence. Int Urogynecol J Pelvic Floor Dysfunct 8 (4):209-212

30. Hoyte L, Thomas J, Foster RT, Shott S, Jakab M, Weidner AC (2005) Racial differences in pelvic morphology among asymptomatic nulliparous women as seen on three-dimensional magnetic resonance images. Am J Obstet Gynecol 193:2035-2040 